\title{
Discourse markers as indicators of connectedness between expositive illocutionary acts
}

\author{
Etsuko Oishi \\ Tokyo University of Science
}

\begin{abstract}
There has been consistent interest in discourse makers over the past couple of decades, and various proposals have been put forth regarding their functions. The present paper analyzes discourse markers in general as indicators of types of connectedness between expositive illocutionary acts (Austin [1962]1975), which bring about illocutionary effects in discourse. The discourse marker well in particular indicates a gap between the preceding expositive illocutionary act and the present one, signaling the present expositive illocutionary act is of a non-committal type. This gap is analyzed, depending on the types of the preceding and present expositive illocutionary acts, as divergence, hesitancy, a transition from one expositive illocutionary act to another, or a boundary between them.
\end{abstract}

Keywords: discourse markers, well, expositives, discursive illocutionary acts, J.L. Austin, speech act theory

\section{Introduction}

The following is a part of President Donald Trump's interview with ABC News on 26 January 2017: ${ }^{1}$

David Muir: What are you gonna say to some of your supporters who might say, "Wait a minute, I thought Mexico was going to pay for this [the wall] right at the start."

President Trump: Well, I'd say very simply that they are going to pay for it. I never said they're gonna pay from the start.

1. http://www.telegraph.co.uk/news/2017/o1/26/full-transcript-president-donald-trumpsinterview-abc-news/ 
Well is a discourse marker among others such as oh, and, but, or, so, because, now, then, I mean, y'know (Schiffrin 1987:31). "Well" in President Trump's utterance above does not contribute to the propositional or truth-conditional content of the utterance, but signals something to do with the discursive function of the utterance: conjointly with his following denial that he had said Mexicans were going to pay for the wall from the start, the utterance is a rebuttal to the preceding criticism of the interviewer that President Trump's supporters would feel betrayed if American taxpayers initially pay for the wall.

The precise identification of the function of the discourse marker well is difficult, and many proposals have been put forward. Blakemore (2002:129) summarizes varied analyses of well as (i) a signal that the speaker has diverged from coherence (Schiffrin 1987) or relevance (Jucker 1993), and, on the contrary, (ii) a signal of acceptance of a norm (Bolinger 1989) or a move in a dialogue game (Carlson 1984). Blakemore (2002: 138) gives her own account as follows:

In contrast with Jucker's (1993) relevance theoretic account which argues that well encodes derivation from optimal relevance and hence is an instruction to renegotiate the context, this [Blakemore's] account will propose that the information it encodes amounts to a green light for going ahead with the inferential processes involved in the recovery of cognitive effects, and the renegotiation of the context may be, but is not always, a consequence of interpreting the utterance in accordance with the constraint which well encodes. (the emphasis is Blakemore's)

Schourup (2001:1050) regards well as the "gestural" interjection that indicates a relationship between a mental state or attitude and "a vocal 'portrayal' of that state." Carter and McCarthy (2006:152) regard well as a discourse marker which "indicate[s] that the speaker is thinking about something."

In her corpus-based analysis of well as a pragmatic marker, ${ }^{2}$ Aijmer (2013:50) provides a more fine-grained analysis of the functions of well. Following Östman (1995), Aijmer identifies three functions for well: (i) coherence, (ii) involvement and (iii) politeness. The coherence function is further divided into (a) transition to a new turn, (b) transition to a new agenda, (c) direct speech, (d) word search and (e) self-repair, while the involvement function is divided into (a) agreeing, (b) disagreeing and (c) insufficient answers.

Why is the function of well so diverse that the linguists give (i) an opposing analysis, as shown by the contrast between Schiffrin (1987) and Jucker (1993), on the one hand, and Bolinger (1989), Carlson (1984) and Blakemore (2002), on the

2. Aijmer (2013:1-4) uses the term pragmatic marker, and pragmatic markers do not only function as discourse markers, but also markers of social, cultural and regional variations. The term discourse particle is used as well (Fischer 2006). 
other, and (ii) provide different types of analysis, as shown by Schourup (2001) and Carter and McCarthy (2006)? How can it be that well performs opposing functions such as agreeing and disagreeing, as Aijmer (2013) suggests?

The reason might be that the researchers have been analysing discourse markers in general, and the discourse marker well in particular, independently without considering (i) what discursive effects are produced by utterances as their illocutionary effects, and (ii) what type of connectedness between discursive illocutionary acts the discourse markers indicate.

One of the two purposes of the present paper is to clarify discursive effects that are produced by utterances as illocutionary acts. Adopting Austin's ([1962]1975) illocutionary act category, we identify discursive illocutionary acts as expositive illocutionary acts, and, employing Austin's list of expositives, explain what discursive effects are produced by each group of expositive illocutionary acts. This is the goal of Section 2.

The other purpose, the goal of Section 3, is to provide a speech-act-theoretic explanation of the functions of discourse markers. We will argue that discourse markers indicate types of connectedness between the preceding expositive illocutionary act and the present one, and thereby signal a particular type for the present expositive illocutionary act. The discourse marker well in particular indicates a gap between the preceding expositive illocutionary act and the present one, signalling that the present act is of a non-committal type. The seeming diversity in the function of well can be attributed to the diversity of discursive illocutionary act types whose relationships well indicates. The discourse maker but as an indicator of a contrast is also analysed in this section. A short concluding section follows.

\section{Discursive illocutionary acts}

\subsection{Expositive illocutionary acts (Austin 1975)}

Unlike Searle's (1979) classification of illocutionary acts, based on propositional contents and the directions of fit, Austin (1975:151-163) classifies illocutionary acts according to the types of effect that they bring about, and distinguishes five classes: verdictives, exercitives, commissives, behabitives and expositives. Verdictives consist in the delivering of a finding, official or unofficial, upon evidence or reasons as to value or fact, as far as these are distinguishable; exercitives are used to give a decision in favour of or against a certain course of action, or advocacy of it; commissives are to commit the speaker to a certain course of action; behabitives include the notions of reaction to other people's behaviour and fortunes and 
of attitudes and expressions of attitudes to someone else's past conduct or imminent conduct; expositives include expounding a view, conducting an argument, and clarifying a usage or a reference.

When expositive illocutionary acts are performed, a view is expounded, an argument is conducted, a usage or a reference is clarified, and so on; there are their illocutionary effects. These effects seem to be brought about in discourse: the acts of expounding, conducting, clarifying, and so on affect the discourse so that it will develop in a particular direction. ${ }^{3}$

Let us illustrate this by an Austinian model. On the basis of Austin's (1975:14-15) felicity conditions (A.1) ("There must exist an accepted conventional procedure having a certain conventional effect, that procedure to include the uttering of certain words by certain persons in certain circumstances, and further"), and (A.2) ("the particular persons and circumstances in a given case must be appropriate for the invocation of the particular procedure invoked"), we distinguish (a) a speaker and (b) a hearer in a given case and (c) circumstances of the speech situation (specified by [A.2]), from $(\alpha)$ the performer of an illocutionary act, $(\beta)$ the target recipient of the illocutionary act, and $(\gamma)$ the context of the illocutionary act (specified by [A.2]), respectively. We refer to the performer of an illocutionary act as the addresser of the illocutionary act, and to the target recipient of the illocutionary act as the addressee of the illocutionary act. In performing an illocutionary act, a speaker assumes (i) her/himself as the addresser of the illocutionary act, (ii) a hearer as the addressee of the illocutionary act, and (iii) the circumstances of the speech situation as the context of the illocutionary act (see Oishi 2014, 2015, 2017). This is shown in Figure 1:

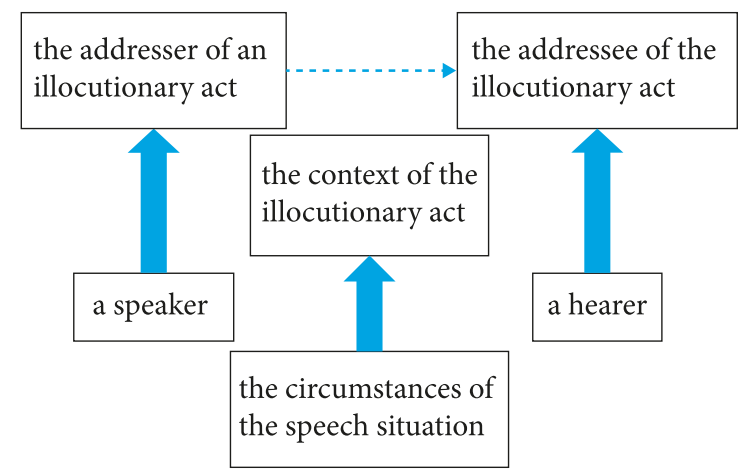

Figure 1. The elements of the illocutionary act

3. This idea is also developed by Oishi $(2014,2015,2017)$ and Oishi and Fetzer (2016). 
Expositive illocutionary acts are discursive illocutionary acts in the sense that they bring about effects which are determined with respect to the illocutionary act of the preceding utterance (or a prior part of the discourse), thereby connecting the present utterance with the preceding one (or the prior part of the discourse). On the basis of the effects to be brought about, they indicate a particular range of illocutionary acts that naturally follow, thereby developing the discourse in a particular direction. Figure 2 illustrates how expositive illocutionary acts connect the present utterance with the preceding one:

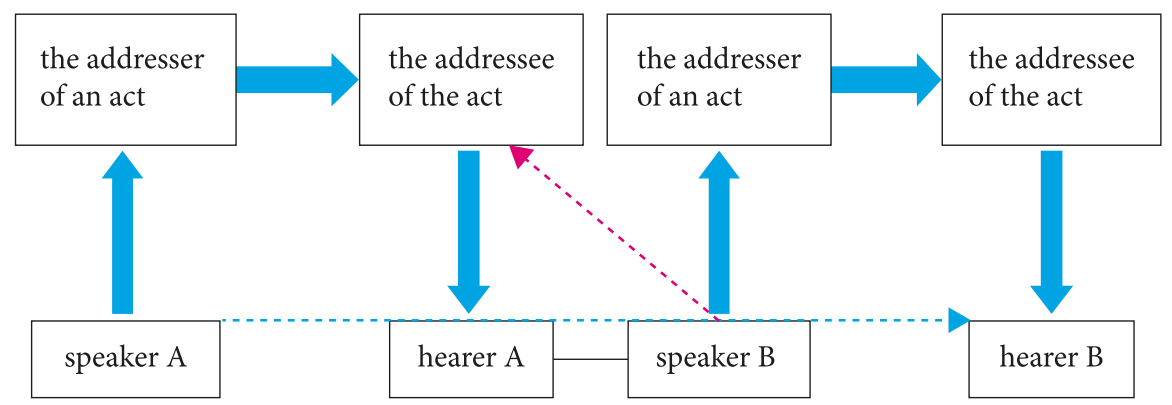

Figure 2. The model of performing an expositive illocutionary act

Speaker B's illocutionary act is a reaction (as hearer A) to speaker A's illocutionary act. Being the hearer who is assumed to be the addressee of the illocutionary act performed by speaker A motivates hearer A, that is, speaker B, to perform a particular expositive illocutionary act. The illocutionary force of speaker B's utterance, therefore, is determined in terms of the illocutionary act of speaker A's utterance. Speaker B's reaction can be to a particular aspect of the discourse that Speaker A's illocutionary act aims to develop.

Through this process of acting and reacting, ${ }^{4}$ a series of illocutionary effects are brought about, and accordingly, the circumstances of the speech situation change: changes are produced as the effects of expositive illocutionary acts, and also some of the circumstances of the speech situation are foregrounded while others are backgrounded. Figure 3 illustrates that the circumstances of the present speech situation motivate a speaker to perform a particular expositive illocutionary act, which brings about an effect on the speech situation. This, in turn, motivates the same speaker (or another speaker) to perform a particular expositive illocutionary act, and this process continues until the talk exchange ends.

4. Expositive illocutionary acts in mediated discourse can bring about effects on participants in the second and third frame (Fetzer 2006) such as participants in a TV studio and TV viewers, but the present paper limits its analytical scope to face-to-face interaction. 


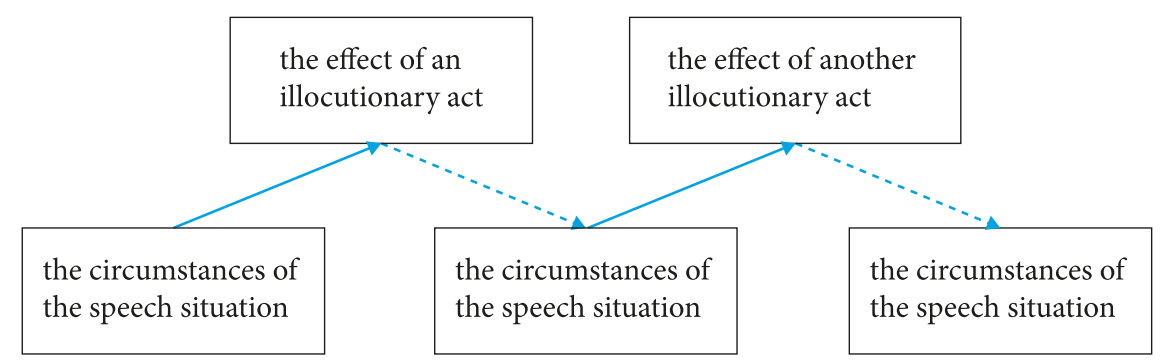

Figure 3. The model of how the effects of expositive illocutionary acts are produced

What types of expositive illocutionary act exist, and what types of effect do they produce? Austin (1975:162) gives the following list of expositives:

1. affirm, deny, state, describe, class, identify

2. remark, mention, ?interpose $e^{5}$

3. inform, apprise, tell, answer, rejoin

a. ask

4. testify, report, swear, conjecture, ?doubt, ?know, ?believe

5. accept, concede, withdraw, agree, demur to, object to, adhere to, recognize, repudiate

a. correct, revise

6. postulate, deduce, argue, neglect, ?emphasize

7. begin by, turn to, conclude by

a. interpret, distinguish, analyse, define

b. illustrate, explain, formulate

c. mean, refer, call, understand, regard as

Is this the list of expositives or the list of expositive verbs in English? It is the list of expositive verbs which embody the distinctions of discursive acts that English speakers have found worth drawing:

... our common stock of words embodies all the distinctions men [sic] have found worth drawing, and the connexions they have found worth marking, in the lifetimes of many generations: these surely are likely to be more numerous, more sound, since they have stood up to the long test of the survival of the fittest, and more subtle, at least in all ordinary and reasonably practical matters.

(Austin [1961]1979:182)

Obviously, this is not an exhaustive list of expositives. There must be expositive illocutionary act types which do not have performative verbs, just as the list of

5. Question marks are Austin's. 
exercitives in English lacks the performative verb verdict (Mey 2001:107). Moreover, this is not a universal list: other languages probably have more or less finegrained distinctions of expositive illocutionary acts. Even so, this is still a good place to start.

Do the groups of expositives in the list (from [1] to [7c]) represent distinct types? Ormson is guarded about this, and says "The general significance of the grouping is obvious but there is no definite key to it in the extant papers" (Austin 1975:162fn.). Let us, however, pursue the idea that Austin distinguishes seven types of expositive illocutionary acts ([1] to [7]) and five sub-types ([3a], [5a] and $[7 \mathrm{a}]$ to $[7 \mathrm{c}])$ to give a general picture of how the speaker can affect the discourse. ${ }^{6}$

\subsection{The characterizations of expositive illocutionary act types}

In the present subsection, we characterize types of expositive illocutionary act according to Austin's (1975) list, by examining their contexts, targets and effects. As example utterances, we use the President Donald Trump's interview with ABC News that was cited in the introduction.

The expositive illocutionary acts in the group (1) of the list, affirming, denying, stating, describing, classing and identifying, are performed in the context in which the truth (or falsity) of there being a particular state of affairs in the world is in question, and, when this type of act is successfully performed, its truth (or falsity) is granted in the discourse. President Trump's utterances "Now we have criminals that are here. We have really bad people that are here" in (1) are acts of affirming that some undocumented immigrants who are criminals/bad people are staying in the U.S.:

(1) David Muir: But Mr. President, will they [undocumented immigrants] be allowed to stay?

President Trump: I'm gonna tell you over the next four weeks. But I will tell you, we're looking at this, the whole immigration situation, we're looking at it with great heart. Now we have criminals that are here. We have really bad people that are here. Those people have to be worried 'cause they're getting out. We're gonna get them out.

As the effects of these acts of affirming, the truth of the affirmed contents is taken for granted in the interview discourse.

The expositive illocutionary acts in group (2) of the list, which include remarking, mentioning and interposing, are the act of giving information or a comment additionally/independently or away from the current flow of the talk

6. Oishi $(2015,2017)$ gives tentative analyses of these types of expositive illocutionary acts. 
exchange. As a response to the preceding question ("Where is the evidence of that?"), President Trump says "So, let me tell you first of all, it was so misrepresented", remarking that his words about illegal votes in the meeting were significantly misrepresented, without giving an answer to the question.

(2) David Muir: I wanna ask you about something you said this week right here at the White House. You brought in congressional leaders to the White House. You spoke at length about the presidential election with them - telling them that you lost the popular vote because of millions of illegal votes, 3 to 5 million illegal votes. That would be the biggest electoral fraud in American history. Where is the evidence of that?

President Trump: So, let me tell you first of all, it was so misrepresented. That was supposed to be a confidential meeting. And you weren't supposed to go out and talk to the press as soon as you - but the Democrats viewed it not as a confidential meeting.

As their conventional effects, the acts of remarking, mentioning and interposing bring the remarked, mentioned, and interposed contents, respectively, to the discourse as additional or independent information, which potentially changes the direction in which the discourse develops. President Trump adds to the interview discourse the information about how his words were reported, and averts the focus of the talk from the evidence of illegal votes.

The expositive illocutionary acts in group (3), informing, apprising, telling, answering and rejoining, aim to bring about effects on the addressee; the addressee is informed, apprised, told, answered, or rejoined. When this type of act is performed successfully, the addressee's possession of the information is taken for granted in the discourse. President Trump's utterance in (3), "It has periodically hit me," is to answer/inform the hearer David Muir as the addressee that he (President Trump) is occasionally devastated by the magnitude of the job of the U.S. President.

(3) David Muir: Let me ask you, has the magnitude of this job hit you yet?

President Trump: It has periodically hit me. And it is a tremendous magnitude.

In the expositive illocutionary act of asking (in group [3a] of the list), on the other hand, the addressee is requested to give information. In saying "Then why did he write the report?", President Trump asks the interviewer why the author of the Pew report wrote it if they found no evidence of voter fraud. 
(4) David Muir: I called the author of the Pew report last night. And he told me that they found no evidence of voter ...

(Overlap)

David Muir: ... fraud.

President Trump: Really? Then why did he write the report?

The expositive illocutionary acts in the group (4), testifying, reporting, swearing and conjecturing, and possibly doubting, knowing and believing, are to give one's knowledge. When this type of act is performed successfully, the information is introduced to the discourse as content the addresser knows and has testified, reported, sworn and so on. President Trump's utterances "I was with the Ford yesterday. And with General Motors yesterday" in the Example (5) are the acts of reporting that he met the top representatives of the Ford/General Motors on the previous day.

(5) President Trump: I was with the Ford yesterday. And with General Motors yesterday. The top representatives, great people. And they're gonna do some tremendous work in the United States.

The expositive illocutionary acts in the group (5), accepting, conceding, withdrawing, agreeing, demurring to, objecting to, adhering to, recognizing and repudiating, are to respond to a prior illocutionary act and/or its contents. David Muir objects to President Trump's criticism that he and other journalists demeaned people in the inaugural crowd.

(6) President Trump: ... Therefore I won't allow you or other people like you to demean that [inaugural] crowd and to demean the people that came to Washington, D.C., from faraway places because they like me. But more importantly they like what I'm saying.

David Muir: I just wanna say I didn't demean anyone who was in that crowd. We did coverage for hours ...

The following utterance "We did coverage for hours" is the act of correcting President Trump's claim by stating that the journalists properly covered the inaugural speech. The expositive illocutionary act of correcting, which is in the group (5a), is to modify a prior illocutionary act and/or its contents, and when it is successfully performed, the modification is brought into the discourse.

The expositive illocutionary acts in the group (6), postulating, deducing, arguing, neglecting and possibly emphasizing, are to present (or not to present) an idea as a logical conclusion. When this type of act is performed successfully, the idea is (or is not) introduced to the discourse as something logically concluded. In the following example, David Muir postulates or argues that talking 
about millions of illegal votes without presenting the evidence is dangerous to the U.S., which President Trump dismisses blatantly by saying "No, not at all."

(7) David Muir: Do you think that that talking about millions of illegal votes is dangerous to this country without presenting the evidence?

President Trump: No, not at all.

The expositive illocutionary acts in the group (7), beginning by, turning to and concluding by, function on the structure of the discourse, in particular, segment the discourse by providing a new topic, or leaving the present topic. When this type of act is performed successfully, a new segment begins or the present segment ends. David Muir tries to bring up a new topic by saying "I wanna ask you about something bigger here" and to introduce it by saying "Does it matter more now ...", which was rejected by President Trump, who says "There's nothing bigger."

(8) David Muir: House Speaker Paul Ryan has said, "I have seen no evidence [of voter fraud]. I have made this very, very clear." Senator Lindsey Graham saying, "It's the most inappropriate thing for a president to say without proof. He seems obsessed with the idea that he could not have possibly lost the popular vote without cheating and fraud." I wanna ask you about something bigger here. Does it matter more now...

President Trump: There's nothing bigger. There's nothing bigger.

The expositive illocutionary acts in the group (7a), interpreting, distinguishing, analyzing and defining, are to examine the information/idea presented to the discourse and give a particular interpretation. When this type of expositive illocutionary act is performed successfully, the interpreted, distinguished, analyzed, or defined information/idea is brought into the discourse. In saying "She [Hilary Clinton] thought she had it [Michigan] in the bag," President Trump interprets or analyzes Hilary Clinton's not having gone to Michigan as the sign that she thought she would win there, and this interpretation is brought into the discourse.

(9) President Trump: ... Now, you have to understand I - I focused on those four or five states that I had to win. Maybe she [Hilary Clinton] didn't. She should've gone to Michigan. She thought she had it in the bag. She should've gone to Wisconsin, she thought she had it because you're talking about 38 years of, you know, Democrat wins. But they didn't. I went to Michigan, I went to Wisconsin. I went to Pennsylvania all the time. I went to all of the states that are - Florida and North Carolina. That's all I focused on.

The expositive illocutionary acts in the group ( $7 b)$, illustrating, explaining and formulating, are to provide an idea to the discourse. When this type of expositive 
illocutionary act is successfully performed, the illustrated, explained, or formulated idea is introduced to the discourse. In the turn which follows President Trump's utterances in (9), David Muir says:

(10) David Muir: Mr. President, it does strike me though that we're relitigating the presidential campaign, the election ....

David Muir illustrates how President Trump strays from the subject of the interview by suggesting that he is debating again on the presidential campaign. This idea is introduced to the discourse.

The expositive illocutionary acts in the group ( $7 \mathrm{c})$, meaning, referring, calling, understanding and regarding as, are to clarify usages and referents, and when this type of act is successfully performed, the specified usages and referents are taken for granted in the discourse. The following example shows that David Muir refers to journalists of $\mathrm{ABC}$ News, not him personally, as the legitimate referents of the pronoun "you" in the preceding utterance of President Trump:

(17) President Trump: ...That speech [at the CIA] was a big hit, a big success success. And then I came back and I watched you on television and a couple of others.

David Muir: Not me personally.

The summary of the characterizations of the expositive illocutionary act types according to Austin's (1975) list is in the following:

Group (1) expositives (affirming, denying, stating, describing, classing and identifying) are to make a statement about the truth (or falsity) of a particular state of affairs in the world.

Group (2) expositives (remarking, mentioning and interposing) are to give information or a comment additionally/independently or away from the current flow of the talk exchange.

Group (3) expositives (informing, apprising, telling, answering and rejoining) are to give the addressee information, and the (3a) expositive of asking is to request the addressee for information.

Group (4) expositives (testifying, reporting, swearing, conjecturing, doubting, knowing and believing) are to give one's knowledge.

Group (5) expositives (accepting, conceding, withdrawing, agreeing, demurring to, objecting to, adhering to, recognizing and repudiating) are to respond to a prior expositive illocutionary act and/or its contents, and the acts of correcting and revising in (5a) are to modify it.

Group (6) expositives (postulating, deducing, arguing, neglecting and emphasizing) are to present (or not to present) a logically concluded idea. 
Group (7) expositives (beginning by, turning to and concluding by) are to segment the discourse by providing a new topic or concluding the present topic.

Group (7a) expositives (interpreting, distinguishing, analyzing and defining) are to examine the information/idea presented to the discourse and give a particular interpretation.

Group ( $7 \mathrm{~b}$ ) expositives (illustrating, explaining and formulating) are to provide an idea to the discourse.

Group ( $7 \mathrm{c}$ ) expositives (meaning, referring, calling, understanding and regarding as) are to clarify usages and referents.

\section{Discourse markers as indicators of the connectedness between the preceding expositive illocutionary act and the present one}

\subsection{The discourse marker but}

We have shown that various discursive effects are produced by diverse types of expositive illocutionary acts, where utterances are connected with the preceding one in various ways, or with various aspects of the discourse. Let us now examine the functions of discourse markers in terms of these diverse types of expositive illocutionary acts. The present section aims to show that discourse markers indicate types of the connectedness between the preceding expositive illocutionary act and the present one, thereby signaling a particular type for the present expositive illocutionary act.

Oishi and Fetzer (2016:56) analyze the discourse marker but as a connective which indicates a contrast, signaling that the upcoming discursive contribution is going to differ from the previous one. Their explanation is as follows: ${ }^{7}$

In discourse analysis, discourse connectives ${ }^{8}$ signal the nature of the connectedness between discursive contributions, between discursive contributions and discourse, between discursive contributions and the addresser/addressee, and between discursive contributions, discourse and context. They are seen as nonpropositional linguistic items, connecting various planes of discourse into a coherent mental picture of discourse. In the exchange between the LO [the leader of the opposition Edward Miliband] and the PM [Prime Minister David

7. See also Fetzer (2011) for the idea that discourse markers have the function of gluing speech acts.

8. Discourse connective is used as an umbrella term comprising discourse marker and pragmatic marker. 
Cameron] analyzed above, but in the PM's contribution "but I notice, $\mathrm{Mr}$ Speaker, I notice, Mr Speaker, that he does not ask about unemployment" is a prototypical discourse connective fulfilling the function of a contrastive connective, expressing anaphoric reference, indicating that the upcoming discursive contribution or one or more of its constitutive parts is going to differ from the previous one. In that respect, discourse connectives are also metacommunicative devices which express higher-level comments, and thus - from a functional perspective - very similar to expositive speech acts, requesting the hearer as the addressee of how the speaker as the addresser intends his/her contribution(s) to be contextualized discursively or taken up, in speech-act-theoretic terms.

Let us examine this function of but by using examples from President Trump's interview with $\mathrm{ABC}$ News:

(18) President Trump: .... And I campaigned on the wall. And it's very important. But that wall will cost us nothing.

David Muir: But you talked - often about Mexico paying for the wall. And you, again, say they'll pay us back. Mexico's president said in recent days that Mexico absolutely will not pay, adding that, "It goes against our dignity as a country and our dignity as Mexicans.” He says ...

(Overlap)

David Muir's utterances "But you talked - often about Mexico paying for the wall ..." are a response to President Trump's act in the preceding turn: the act of informing (or reassuring) him as the addressee that the wall will not cost American taxpayers anything. David Muir's utterances are the act of referring to the statements of President Trump (specifying their contents), and to the statement of Mexico's president. "But" indicates a contrast between David Muir's being the addressee of the act of informing (or reassuring) and his being the addresser of act of referring, whose contents differ from or contradict the contents of the information (or reassurance) given by the preceding turn. This is illustrated by Figure 4 in the following:

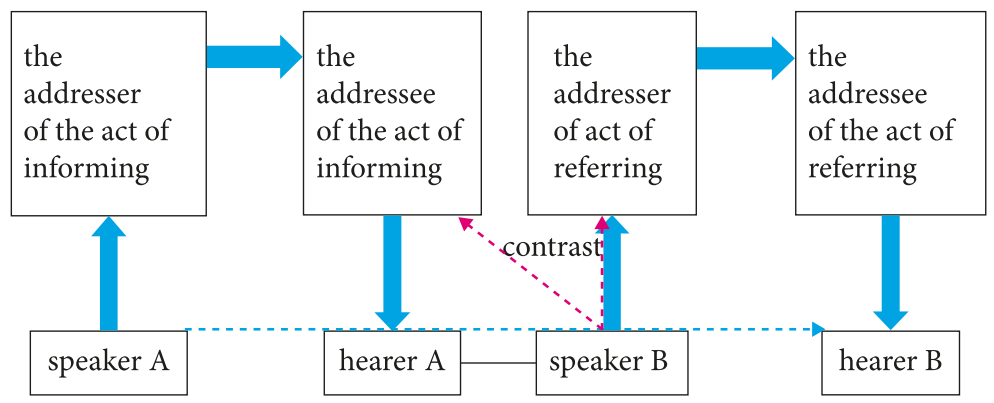

Figure 4. The model of the function of but at a turn-initial place 
"But" in David Muir's utterance, which indicates the contrast, signals the type of the present expositive illocutionary act: it diverges from the preceding act of informing (or reassuring), and it is of a disputative type.

The discourse marker but can indicate a contrast between the two consecutive expositive illocutionary acts performed by the same speaker. "But" in "But that wall will cost us nothing" in the Example (18) above indicates a contrast between President Trump's being the addresser of the preceding illocutionary act of interpreting the wall (or the policy of building the wall) as significant and his being the addresser of the present act of informing (or reassuring) that the wall will not cost American taxpayers anything. This is illustrated by Figure 5 .

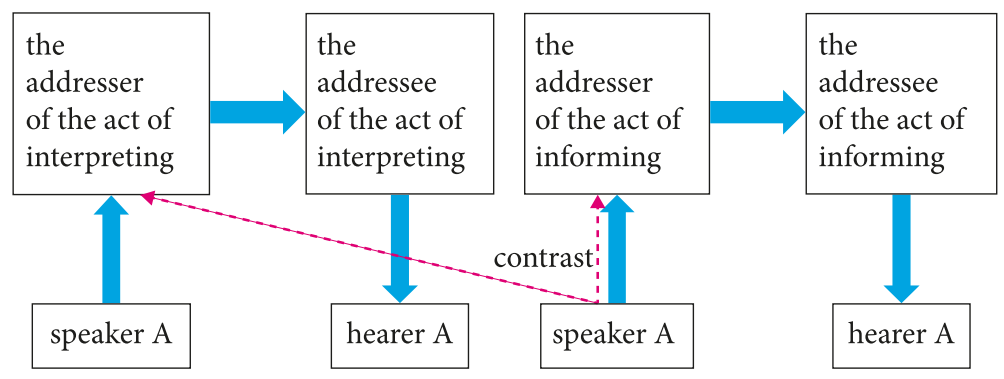

Figure 5. The model of the function of but within a turn

"But" in President Trump's utterance signals that the present illocutionary act diverges from the preceding act of interpreting, and it is of a mitigating type.

In the following section, we will analyze the discourse marker well similarly as an indicator of the connectedness between the preceding expositive illocutionary act and the present one, signaling the type of the present expositive illocutionary act. ${ }^{9}$

\subsection{The functions of the discourse marker well}

The discourse marker well seems to indicate a gap between the addressee (or the addresser) of the preceding expositive illocutionary act and the addresser of the present one. It thereby signals that the present illocutionary act is of a non-committal type, and the present speaker does not fully accept the preceding expositive illocutionary act or/and its contents. To see how this occurs, consider the utterance cited in the introduction.

9. Green (2006:118-119) distinguishes two kinds of discourse markers: attitudinal discourse markers and structural discourse markers. The former (well, uh, like, gush, oh, OK, I mean and $y^{\prime}$ know) indicates "something about how the speaker feels about what is being said," while the latter (now, OK, and, but) indicates "a structural boundary in the discourse." 
(19) David Muir: What are you gonna say to some of your supporters who might say, "Wait a minute, I thought Mexico was going to pay for this [the wall] right at the start."

President Trump: Well, I'd say very simply that they are going to pay for it. I never said they're gonna pay from the start.

"Well” indicates a gap between President Trump's being the addressee of David Muir's act of criticising and his being the addresser of the act of rebutting it, which is based on the claimed inaccuracy of David Muir's specification of the contents of President Trump's prior statement. "Well” signals that President Trump does not fully accept the preceding illocutionary act of criticizing and its contents. This is illustrated by Figure 6:

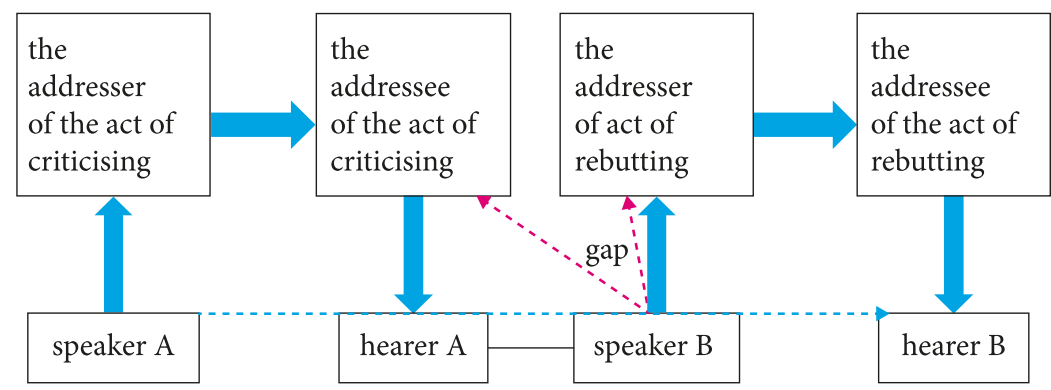

Figure 6. The model of the function of well

There is another example of well in President Trump's interview.

(20) David Muir: But 3 to 5 million illegal votes?

President Trump: Well, we're gonna find out. But it could very well be that much. Absolutely.

"Well" indicates a gap between President Trump's being the addressee of David Muir's act of asking (whether or not there were three to five million illegal voters) and his being the addresser of the act of predicting (the Trump administration is going to find out how many illegal voters were there). "Well" signals that the present expositive illocutionary act is of a non-committal type: President Trump does not give a straightforward answer to the question asked.

Let us see if this explanation applies to some other examples of well from previous studies. The following examples are from Blakemore (2002:130-31):

(21) Passenger: A $£ 1.20$ please.

Bus-driver [after failing to get the ticket machine to work several

times]: Sorry, it's brand-new machine, and it's playing up.

Passenger: Well, what do I do? 
(22) A: How long have you two been married?

B: Well, actually we're not.

(23) A: Anna's much taller than Verity.

B: Well, she is two years older.

"Well" in the passenger's utterance in (21) indicates a gap between the addressee of the act of informing (the ticket machine is brand new, and it is not functioning properly) and the addresser of the act of asking. "Well" signals that the present expositive illocutionary act's function is of a non-committal type, and the passenger does not fully accept the preceding illocutionary act of informing (obtaining the information does not make the situation better).

"Well" in Speaker B's utterance in (22) indicates a gap between the addressee of the act of asking (how long the addressees have been married) and the addresser of correcting the question, more specifically, the presupposition of the question. "Well" signals that the present expositive illocutionary act is of a noncommittal type, and Speaker B does not fully accept the preceding illocutionary act of asking (the presupposition is wrong).

"Well" in Speaker B's utterance in (23) indicates a gap between the addressee of the act of describing (Anna as taller than Verity) and the addresser of analysing the description. "Well" signals that the present expositive illocutionary act is of a non-committal type, and Speaker B does not fully accept the description (Anna is two years older than Verity).

The proposed explanation of the function of well is compatible with the varied characterizations of the function of well that we introduced in Section 1. What well signals can be interpreted as the indication of divergence from coherence or relevance (Schiffrin 1987; Jucker 1993) in the sense that it signals that the present illocutionary act is of a non-committal type and the present speaker does not fully accept the preceding expositive illocutionary act or/and its contents. However, well signals something communicative: it signals how to revise the preceding expositive illocutionary act and its presuppositions about the circumstances of the speech situation so that the present speaker can agree with the speaker of the preceding utterance and they can cooperatively develop the discourse in a particular direction. In this sense, what well signals can be described as acceptance of a norm (Bolinger 1989) (of communication), or a move in a dialogue game (Carlson 1984), or as "a green light for going ahead with the inferential processes involved in the recovery of cognitive effects" (Blakemore 2002:129). It is also possible to interpret the perceived gap between the preceding illocutionary act and the present one as the speaker's mental state or attitude, which well indicates as a "gestural" interjection (Schourup 2001). The gap indicated by well can be interpreted as a sign of a speaker's thinking about something (Carter and McCarthy 2006). 
The proposed explanation is also compatible with Aijmer's (2013) functional analysis. As we introduced in Section 1, Aijmer identifies the functions of well as (i) coherence, (ii) involvement and (iii) politeness, and the function of coherence is further divided into (a) transition to a new turn, (b) transition to a new agenda, (c) direct speech, (d) word search and (e) self-repair, while the involvement function is divided into (a) agreeing, (b) disagreeing and (c) insufficient answers.

Let us start by analysing the coherence function. When the present expositive illocutionary act's function is to segment the discourse, which we refer to as the group ( 7 ) expositive type (e.g. beginning by, turning to and concluding by), well can indicate a transition to (i) a new turn (of the act of segmenting), (ii) a new agenda (of the new segment), and (iii) a quotation (as a new segment). This is explained by the examples from (24) to (26) in the following (Aijmer 2013: 33-35): ${ }^{10}$

(24) A: Can you tell me how did you both get involved in the Mike Heafy project $<,>^{11}$
B: Shall I go first
C: Yes
B: Well ${ }^{12}$ I got involved through Celeste who $<,>^{13}$ I used to dance with with London Contemporary $<,>$ going back $<,>$ twenty years or so

"Well" in (24) indicates a gap between the addressee of the illocutionary act of agreeing (with the suggestion that Speaker B will speak first) in the preceding turn and the addresser of the act of beginning a new segment of the discourse (by explaining how speaker $\mathrm{B}$ and speaker $\mathrm{C}$ got involved in the Mike Heafy project) in the present turn, thereby indicating a transition to the present turn of beginning a new segment.

The exchange in (25) is between a doctor (speaker A) and a patient (speaker B):

(25) A: A sore throat

Well how old were you when the tonsils were taken out

B: Well I had them taken out <,> in January

A: This year

B: Yeah

10. The examples from (24) to (30) are all from Aijmer (2013:32-38, 41-2)

11. $<$,, $>$ indicates a long pause.

12. The emphasis on well (as "well" or in "well I mean" and "uh $<$, , $>$ well") in all of the examples is Aijmer's.

13. $<,>$ indicates a short pause. 
Aijmer (2013:35) describes the function of "well" in (25) as "mark[ing] transitions between stages". The first occurrence of "well" (in Speaker A's utterance) indicates a gap between the addresser of the preceding illocutionary act of acknowledging the patient's problem (a sore throat), and the addresser of the present illocutionary act of beginning a new segment of the discourse (by asking the time when the patient had the tonsils removed): what "well" indicates can be analysed as a transition to a new agenda of the new segment. The second occurrence of "well" (in Speaker B's utterance), however, seems to indicate the gap caused by a wrong assumption. The gap is between the addressee of the act of asking (how old Speaker B was when s/he had the tonsils removed), which is seemingly performed on the assumption that Speaker B had the tonsils removed when s/he was young, and the addresser of the expositive illocutionary act of answering the question (by saying s/he had them removed in January [this year]).

Well can also mark direct speech (as a boundary function) when the expositive illocutionary act of segmenting the discourse is performed.

(26) And I said oh really $<,>$

And uhm and he said $<$, > well what do you think Jenny

And I thought oh God

And I said <,> well I couldn't say no you're not boring because it was so obvious

Both occurrences of "well" indicate a gap between the addresser of the expositive act of reporting ("he said" and "I said") and the addresser of the illocutionary act of beginning a new segment (a direct speech) by giving the contents of the reports.

Norrick (2001: 857) describes the function of well in oral narratives as a staging function, which can be interpreted to indicate a gap as a transition made by the expositive illocutionary act of segmenting the discourse: well can lead into beginnings and endings of oral narratives and mark a return to the main theme of the story.

Well can indicate a transition to a new discourse when the new discourse commences with the present expositive act, where well indicates a gap between a nonverbal prelude to a talk exchange and the discourse that has just begun.

Well can also signal self-repair when the expositive illocutionary act of correcting or revising (the group [5a] expositive illocutionary act type) is performed by the present utterance.

(27) A: Well Xepe seems to love this idea of having a picnic but I'm not too sure about this.

B: Not if you've had lunch 
A: Because I'll have eaten any way

Well I mean part part of the reason I am eating will be so that I we don't have a picnic

"Well" indicates a gap between the addresser of the preceding illocutionary act of explaining the reason (Speaker A will not have a picnic because s/he will have eaten) and the addresser of the illocutionary act of (self-)revising (or [self-]repairing) the explanation ( $\mathrm{s} / \mathrm{he}$ is going to eat so that s/he won't have a picnic).

The discourse marker well can occur in the middle of an utterance, whose function Aijmer describes as marking a word-search. This function can be explained as indicating a gap when the illocutionary act of clarifying usages or referents (the group ( $7 \mathrm{c}$ ) expositive illocutionary act type) is performed as a part of the main expositive illocutionary act.

(28) A: One's about the human brain and language. And the other's about uh this

guy called Chomsky who's uh $<,,>$ well one of the world's most important

human beings if you happen to be interested in linguistics.

The speaker performs the act of clarifying the referent of "Chomsky" as a part of the main expositive illocutionary act of reporting or explaining, and the gap between the addressers of these acts is indicated by "well".

Let us move on to the involvement function, which Aijmer (2013:37-41) divides into (a) agreeing, (b) disagreeing and (c) insufficient answers. The following is an example of the function of agreeing:

(29) (Speaker B is describing how the French prepare coffee)

B: They had a tendency to cook their coffee in saucepans $<,>$

Make their coffee I should say in saucepans

A: Well they bring it to the boil and whip it off the stove

B: Mm something like that

"Well" in Speaker A's utterance indicates a gap between the addressee of the preceding illocutionary act of explaining or illustrating (how the French prepare coffee) and the addresser of the present illocutionary act of revising the explanation or illustration. The function of "well" in this example can be interpreted as marking agreement because the gap is small enough for Speaker A to be able to modify the contents of the preceding expositive act. Well indicates disagreement, on the other hand, when there is a sizable gap between the addressee of the preceding expositive illocutionary act and the addresser of the present one, as between President Trump's being the addressee of the act of criticising and his being the addresser of the act of rebutting in the Example (19). 
The last involvement function is to mark insufficient answers. Well, which indicates a gap, signals an insufficient answer when the preceding act is asking (the group [5a] expositive illocutionary act type), and the present expositive illocutionary act is not the act of giving the addressee information (the group [5] expositive illocutionary act type).

(30) A: Where else do you look John

B: Well uhn just looking

That's really kind of uh quite specific really cos they have a certain sort of job and that

\section{A: That's your main source}

"Well" indicates a gap between the addressee of the preceding expositive illocutionary act of asking (where else Speaker B looks) and the addresser of the present one, which is not clear but obviously not the act of answering or informing the addressee.

Aijmer (2013:42) identifies the politeness function:

The motive for well may be to soften a potentially face-threatening act or to reinforce it (e.g. in an argument). However, in both cases something must be added to well to show how it is intended. Combinations such as well I don't know, well I think, well perhaps, well maybe and well you know occur and have the function of mitigating illocutionary force in contexts which can be experienced as facethreatening.

Aijmer's observation of politeness function of well can be explained adequately using the proposed explanation. As we have described, the gap indicated by well is wide, spreading from a gap between criticising and objecting to a gap between illustrating and revising, and there are numerous types of gap which indicate a transition from one expositive illocutionary act to another. Therefore, it is necessary in some speech situations to specify the characteristics of the gap by combining well with some other words as a mitigating device (Caffi 2007), and to indicate that the gap is not confrontational or face-threatening.

\section{Conclusion}

We have put forward the idea that discourse markers in general indicate types of the connectedness between the preceding expositive illocutionary act and the present one, and well in particular indicates a gap between them, which is recognized by the present speaker as a gap between the addressee/addresser of the preceding expositive illocutionary act and the addresser of the present one. The 
gap is analyzed, depending on the types of the preceding and present expositive illocutionary acts, as divergence, hesitancy, a transition from one expositive illocutionary act to another, or a boundary between them.

As we examined, there are many types of expositive illocutionary act, and their target effects vary considerably. They are acts of asserting the truth of something being the case, giving information independently, providing the addressee with information and so on. The discourse develops in a particular direction owing to the effects of these various expositive illocutionary acts. Using discourse markers which indicate the nature of the connectedness between the preceding illocutionary act and the present one, thereby signaling the type of the present expositive illocutionary act, discourse participants manage communicative interaction, and share understandings and assumptions brought into the discourse.

The present paper has shown that the discourse marker well indicates a gap between the addressee (or addresser) of the preceding illocutionary act and the addresser of the present one, thereby signaling that the present illocutionary act is a non-committal (or mitigating) type. The prosody of well and words collocated with well may signal what type of gap is indicated by well, such as divergence, hesitancy, and a transition, and there may be some text-type specific interpretations of the gap indicated by well. These should be investigated in future research. Other discourse markers as indicators of types of connectedness of expositive illocutionary acts should be also investigated as the result of such research will contribute to the explication of different ways one expositive illocutionary act is connected with another, and how the discourse develops accordingly. This will provide a better understanding of the nature of the discourse, and how it develops in a particular direction.

\section{Acknowledgements}

I am grateful to my anonymous reviewers for their helpful comments on a former version of the present paper.

\section{References}

Aijmer, Karin. 2013. Understanding Pragmatic Markers: A Variational Pragmatic Approach. Edinburgh: Edinburgh University Press.

Austin, J.L. [1962] 1975. How to Do Things with Words. Oxford: Oxford University Press.

Austin, J.L. [1961] 1979. Philosophical Papers. Oxford: Oxford University Press.

Blakemore, Diane. 2002. Relevance and Linguistic Meaning: The Semantics and Pragmatics of Discourse Markers. Cambridge: Cambridge University Press. https://doi.org/10.1017/CBO9780511486456

Bolinger, Dwight. 1989. Intonation and its Uses: Melody in Grammar and Discourse. Stanford: Stanford University Press. 
Caffi, Claudia. 2007. Mitigation. Amsterdam: Elsevier.

Carlson, Lauri. 1984. "Well" in Dialogue Games: A Discourse Analysis of the Interjection "Well" in Idealized Conversation. Amsterdam and Philadelphia: John Benjamins. https://doi.org/10.1075/pb.v.5

Carter, Ronald and Michel McCarthy. 2006. Cambridge Grammar of English: A Comprehensive Guide. Cambridge: Cambridge University Press.

Green, Georgia M. 2006. "Discourse Particles and the Symbiosis of Natural Language Processing and Basic Research.” In Drawing the Boundaries of Meaning: Neo-Gricean Studies in Pragmatics and Semantics in honor of Laurence R. Horn, ed. by Betty J. Birner, and Gregory Ward, 117-135. Amsterdam: John Benjamins. https://doi.org/10.1075/slcs.80.08gre

Fetzer, Anita. 2006. “'Minister, we will see how the public judges you.': Media references in political interviews." Journal of Pragmatics 38: 180-195. https://doi.org/10.1016/j.pragma.2005.06.017

Fetzer, Anita. 2011. "Here is the difference, here is the passion, here is the chance to be part of a great change': Strategic context importation in political discourse." In Context and Contexts: Parts Meet Whole?, ed. by Anita Fetzer, and Etsuko Oishi, 115-146. Amsterdam: John Benjamins. https://doi.org/10.1075/pbns.209.08fet

Fischer, Kerstin (ed). 2006. Approaches to Discourse Particles. Amsterdam: Elsevier.

Jucker, Andreas H. 1993. “The discourse marker well: A relevance theoretical account." Journal of Pragmatics 19: 435-52. https://doi.org/10.1016/0378-2166(93)90004-9

Norrick, Neal R. 2001. "Discourse markers in oral narrative." Journal of Pragmatics 33: 849-78. https://doi.org/10.1016/S0378-2166(01)80032-1

Mey, Jacob. 2001. Pragmatics: An Introduction 2nd ed. Oxford: Blackwell.

Oishi, Etsuko. 2014. "Evidentials in entextualization." Intercultural Pragmatics 11(3): 437-62. https://doi.org/10.1515/ip-2014-0020

Oishi, Etsuko. 2015. "Follow-ups as speech acts in mediated political discourse." In The Dynamics of Political Discourse: Forms and functions of follow-ups, ed. by Anita Fetzer, Elda Weizman, and Lawrence N. Berlin, 33-58. Amsterdam: John Benjamins. https://doi.org/10.1075/pbns.259.02ois

Oishi, Etsuko. 2017. “Illocutionary effects, presupposition, and implicature." In Pragmatics at its Interfaces, ed. by Stavros Assimakopoulos, 71-88. Boston/Berlin: Walter de Gruyter. https://doi.org/10.1515/9781501505089-005

Oishi, Etsuko and Anita Fetzer. 2016. "Expositives in discourse after discourse" Journal of Pragmatics 96: 49-59. https://doi.org/10.1016/j.pragma.2016.03.005

Östman, Jan-Ola. 1995. "Pragmatic particles twenty years after." In Organization in Discourse: Proceedings from the Turku conference, ed. by Brita Wårvik, Sanna-Kaisa Tanskanen, and Risto Hiltunen, 95-108. Turku: University of Turku.

Schiffrin, Debora. 1987. Discourse Markers. Cambridge: Cambridge University Press. https://doi.org/10.1017/CBO9780511611841

Schourup, Lawrence. 2001. "Rethinking well." Journal of Pragmatics 33: 1026-6o. https://doi.org/10.1016/So378-2166(oo)0oo53-9

Searle, John R. 1979. Expression and Meaning: Studies in the Theory of Speech Acts. Cambridge: Cambridge University Press. https://doi.org/10.1017/CBO9780511609213 


\title{
Address for correspondence
}

\author{
Etsuko Oishi \\ Tokyo University of Science \\ Department of Liberal Arts \\ Faculty of Science \\ 1-3 Kagurazaka \\ Shinjuku, Tokyo 162-0825 \\ Japan \\ oishi@rs.tus.ac.jp
}

\section{Biographical note}

Etsuko Oishi is a professor of linguistics at Tokyo University of Science. She has been developing Austin's speech act theory, focusing on context and contextualization, discourse analysis, modality and evidentiality, indexicality, and implicature. She has published articles on context, appropriateness, apologies, evidentiality and modality, referring and predicating, expositives, and indexicality. She contributed her paper of apologies to Handbooks of Pragmatics, The Pragmatics of Speech Actions (edited by Marina Sbisà and Ken Turner). She is the co-editor (with Anita Fetzer) of Context and Contexts: Parts Meet Whole? (Benjamins 2011). As a guest editor, she co-edited (with Anita Fetzer) the special issue of evidentiality in discourse in Intercultural Pragmatics (2014). 